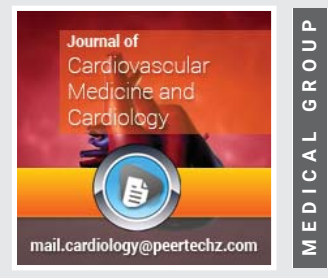

\title{
Use of heart rate variability in biomedical training control
}

\author{
Jaime Gallo-Villegas* \\ Faculty of Medicine, University of Antioquia; SICOR Clinical and Research Center, Medellín, Colombia
}

Received: 19 June, 2020

Accepted: 02 July, 2020

Published: 03 July, 2020

*Corresponding author: Jaime Gallo-Villegas, Faculty of Medicine, University of Antioquia; SICOR Clinical and Research Center, Medellín, Colombia, Tel: +(57)-300618-3590; E-mail: jaime.gallo@udea.edu.co

Keywords: Heart rate variability; Training; Spectral analysis; Heart rate; Prescription of exercise; Overtraining

https://www.peertechz.com

\section{Abstract}

Physical training generates physiological changes throughout the body in order to improve physical performance. Nevertheless, the response to physical training is heterogeneous due to factors related to training and recovery, and individual and contextual factors. Heart Rate Variability (HRV) is an indicator of the sympathetic-vagal balance that has been used for an efficient prescription of exercise in the general population and for the control of training in high performance athletes. In this article, we review the available methods of HRV analysis (time domain, frequency domain and nonlinear dynamics) and the current recommendations for its practical application.

\section{Introduction}

Physical training generates physiological changes throughout the body in order to improve physical performance. The repetitive stimulus of training loads produces hemodynamic and autonomic adaptations necessary to satisfy the metabolic requirements during exercise. Nevertheless, the response to physical training is heterogeneous [1,2]; high variability of maximum oxygen consumption [1] and cross-sectional area of skeletal muscle in response to aerobic training and strength training [2] has been described, respectively.

Different variables explain the heterogeneity of the response to physical training, as follows: i) factors related to training (type, intensity, frequency and duration) and recovery (physical capacity, sleep and stress); ii) individual factors (demographic, phenotypic, genomic, diseases, medications and lifestyle); and iii) contextual factors (environment and socioeconomic) [3]. The identification of these factors lies in the possibility of making a prescription of the exercise and control of stratified training (stratified, personalized or precision medicine) and individualized (individualized medicine), more effective and safer [3,4].

The ability to adapt to physical training depends fundamentally on the integration of neuro-endocrine functions [5]. The autonomic nervous system (ANS) (sympathetic-vagal balance) and the relationship between anabolic and catabolic functions given by hormones such as testosterone and cortisol have a high importance [5]. When there is an imbalance between training loads and recovery, we can observe an activation of sympathetic ANS and a predominance of a catabolic state, in short and long term, respectively [5].

Heart rate variability (HRV) is an indicator of the sympathetic-vagal balance that has been used for an efficient prescription of exercise in the general population and for the control of training in high performance athletes [6,7]. From HRV measurements it has been possible to adjust the intensity and volume of the training in an efficient way to increase the physical work capacity and the maximum oxygen consumption in the general population [6,8-10]. An increase in the sympathetic tone can identify athletes at risk of overtraining [11]. The knowledge of the sympathetic-vagal balance day by day, gives relevant information of the way people are adapting to the training that allows to take opportune decisions in the modulation of the load.

In this article, we review the available methods of HRV analysis (time domain, frequency domain and non-linear dynamics) and the current recommendations for their use in the prescription of exercise and control of training.

\section{Heart rate varibility}

HRV or RR variability is defined as the variation that occurs in the period between consecutive heartbeats [12] (Figure 1). 
Different methods have been used to quantify HRV which have been classified in the time domain, frequency domain and non-linear dynamics [13] (Figure 2). Time domain methods employ statistical measurements (SDNN [standard deviation of all RR intervals]) or geometric measurements (HRV triangular index [total number of all RR intervals divided by the height of the histogram of all RR intervals measured on a discrete scale] derived directly from the $\mathrm{RR}$ intervals or from differences between the adjacent RR intervals of the electrocardiogram (RMSSD [the square root of the mean of the sum of the squares of differences between adjacent RR intervals]; NN50 count [number of pairs of adjacent RR intervals differing by more than $50 \mathrm{~ms}$ in the entire recording]; pNN50 [NN50 count divided by the total number of all RR intervals]) [13] (Figure 2).

The spectral analysis of the HRV is a technique in the frequency domain that allows for obtaining quantitative information on the functioning of ANS [13]. The spectral analysis studies the variables according to their frequency of oscillation. When this technique is applied to the variations of the heart rate in registers of short duration ( 5 minutes), two main spectral components are detected: i) the component between 0.04 and $0.15 \mathrm{~Hz}$ called low frequency (LF) ; and ii) the component between 0.15 and $0.4 \mathrm{~Hz}$ called High Frequency (HF) [13]. The quantification of these spectral components mainly gives information on the neural control of the heart rate. Humoral factors such as circulating catecholamines and circulating non-adrenergic non-cholinergic factors do not play a role in the determination of HRV [13]. Experimental data have shown that the HF component of HRV is mainly determined by the parasympathetic ANS, while the LF component of the HRV, is related to both the sympathetic and the parasympathetic ANS [13]. For this reason, the best indicator of the sympatheticvagal balance in the frequency domain is the LF / HF ratio [13] (Figure 2).

Non-linear phenomena are certainly involved in the genesis of HRV [13]. They are determined by complex interactions of haemodynamic, electrophysiological and humoral variables, as well as by autonomic and central nervous regulations [13]. It has been speculated that analysis of HRV based on the methods of non-linear dynamics might elicit valuable information for the physiological interpretation of HRV and for prescription of exercise and control of training [9]. The parameters which have been used to measure non-linear properties of HRV include $1 / \mathrm{f}$ scaling of Fourier spectra and $\mathrm{H}$ scaling exponent. For data representation, Poincaré sections (SD1 and SD2), lowdimension attractor plots, singular value decomposition, and attractor trajectories have been used [13]. For other quantitative descriptions, the D2 correlation dimension and Kolmogorov entropy have been employed [13]. Entropy is a tool for the analysis of non-linear signals, which provides an independent model to measure the irregularity and complexity of different over-time series [13] (Figure 2).

Measurements in the time domain (SDNN [ms] and RMSSD [ms]), frequency domain (HF component [\%] and LF / HF ratio) and nonlinear dynamics (SD1 of the Poincaré sections [ms]) of HRV have been used in the evaluation of the effect of training [14], the prediction of competitive outcome [15], the physiological profiling $[16,17]$, in the prescription of exercise [9], and the training control [11]. In general, physical training increases vagal activity and HRV ( $\uparrow$ SDNN; $\uparrow$ RMSSD; $\uparrow$ pNN50; $\uparrow \mathrm{HF}$; $\uparrow \mathrm{SD} 1$ ), while a progressive increase in intensity in training loads increases sympathetic activity and decreases HRV ( $\downarrow$ SDNN; $\downarrow$ HF; $\uparrow$ LF / HF ratio) during undisturbed rest [7] (Figure 2). The HRV response during training may be related to adaptations of the respiratory system [16].

\section{Prescription of the exercise: general population}

Currently, the American College of Sports Medicine recommends that the general population perform 150 minutes per week of physical activity at a moderate intensity or 75 minutes per week of physical activity at moderate to high intensity to obtain the benefits of exercise [18]. However, this recommendation does not take into account individual differences in response to training and recovery from physical stimuli.

In recent years, some publications have shown that

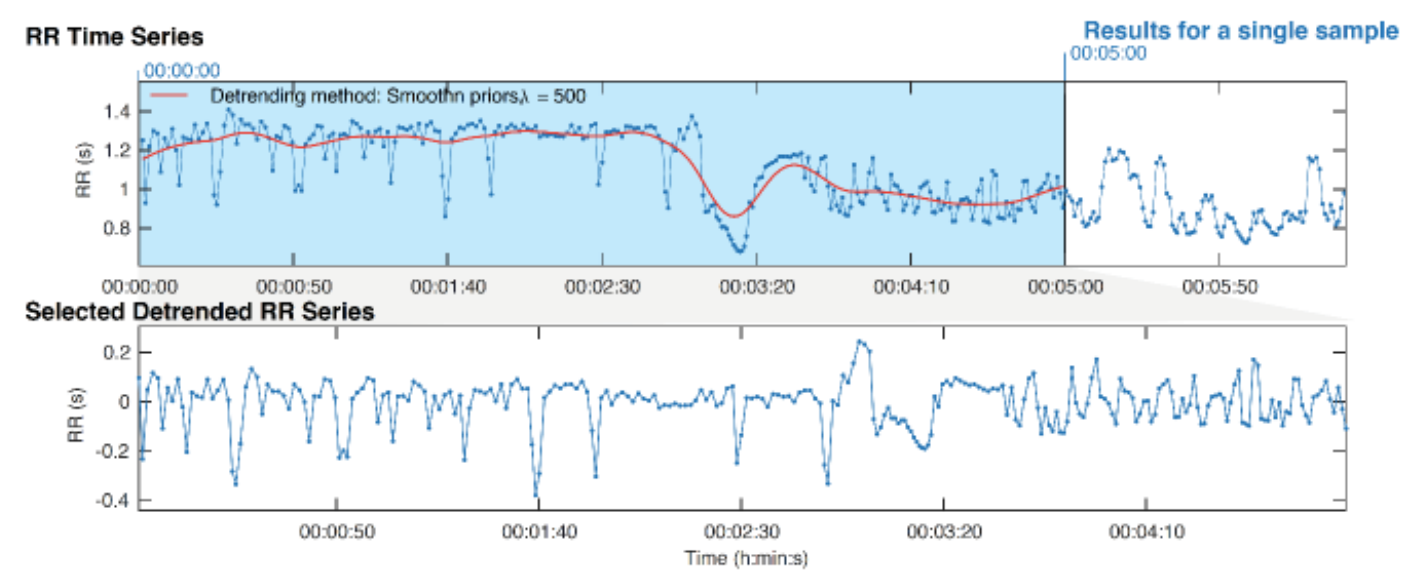

Figure 1: Recording of the heart rate variability with a heart rate monitor Polar ${ }^{\circledR}$ RS800CX (Polar ${ }^{\oplus}$, Kempele, Finlandia) of a professional soccer player during 3 min in the supine position and $3 \mathrm{~min}$ in the standing position. The figure shows the RR interval over time (tachogram). The analyzes were carried out with the software Kubios HRV version 3.3.1 (Kubios ${ }^{\oplus}$, Kuopio, Finland). 


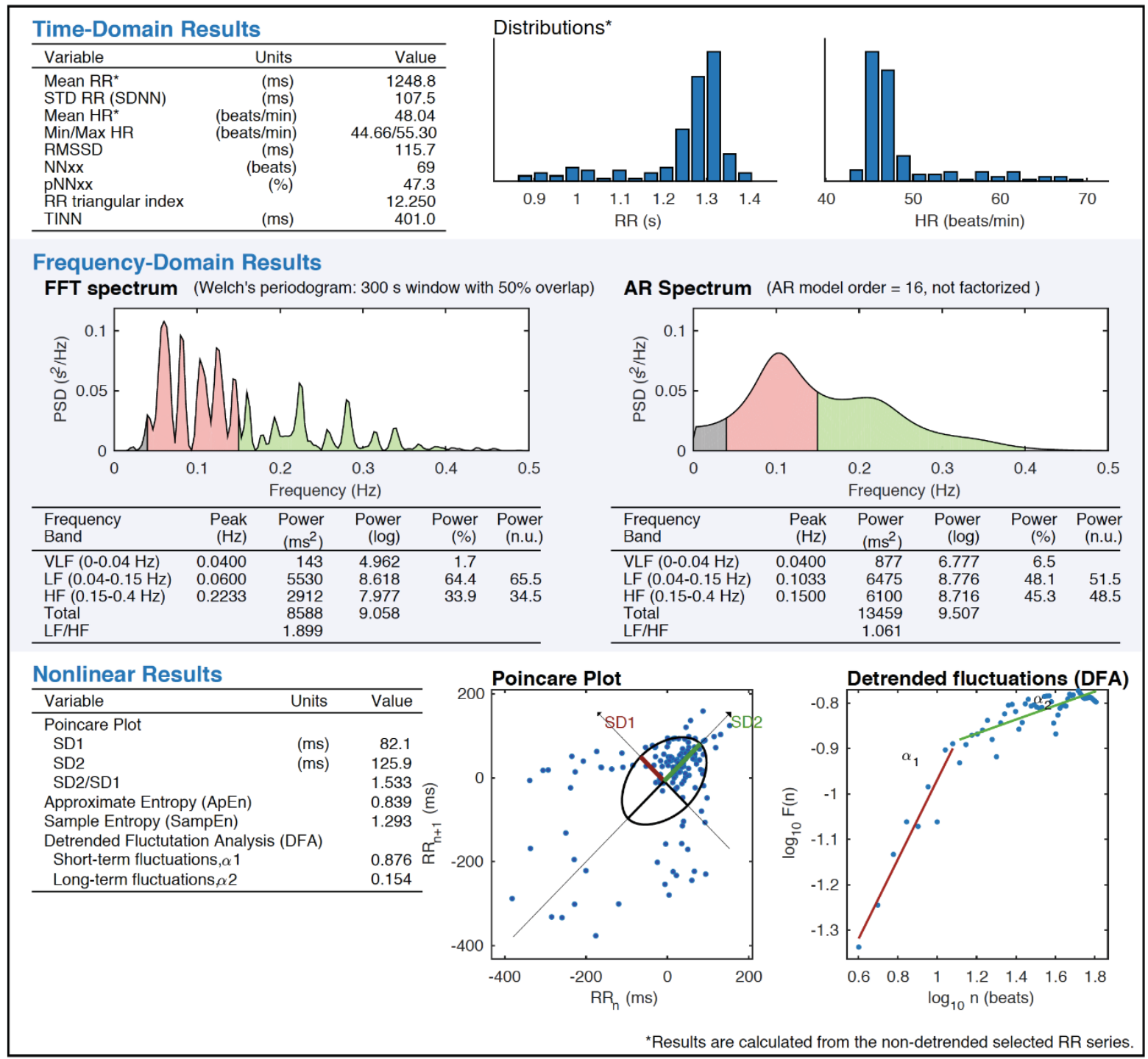

Figure 2: Heart rate variability analysis. The figure shows time domain, frequency domain, and nonlinear dynamics analysis of heart rate variability of a professional soccer player during $3 \mathrm{~min}$ in the supine position. The analyzes were carried out with the software Kubios HRV version 3.3.1 (Kubios ${ }^{\varpi}$, Kuopio, Finland).

aerobic training guided individually by heart rate variability measurements on a daily basis can be more efficient by requiring less intensity and volume to increase the maximum physical workload and maximum oxygen consumption [6,810].

Different measurements of HRV have been used to adjust the training load daily, among which are: i) HF component of the spectral analysis [6]; ii) SD1 of the Poincaré sections [9]; iii) combined score based on several measurements of the spectral analysis [8]; and iv) the RMSSD [10] (Figure 2). Decreasing these HRV indices related to vagal tone indicates negative adaptations to aerobic training and the need to adjust the load (volume or intensity). Today we have different devices, such as smart watches, that facilitate the adjustment of the training load in the general population. Although these measurements have advantages and disadvantages, the most important is the knowledge of the individual variability of each of them over time, before making decisions.

\section{Training control: Overtraining in athletes}

Overtraining is defined as an imbalance between training and recovery leading to deterioration in performance [5]. As part of the pathophysiology, a hypothalamus-pituitary dysfunction has been described in overtraining athletes. The plasma cortisol, ACTH, GH, and PRL responses to insulininduced hypoglycemia in overtrained athletes were lower than their responses after the rest and lower than the responses of the asymptomatic athletes [19]. This involves functional disturbance in organs and systems characterized by various neuro-endocrine clinical manifestations [5,19].

HRV is a marker of sympathetic-vagal balance [13]. Different measurements have been used to detect early sympathetic overactivation indicating physical overload or overtraining [11]. Nevertheless, the first investigations in this regard, have shown inconsistent results, due to difficulties and methodological limitations of the designs of the studies $[11,20]$.

Indices of HRV show a natural daily variation in athletes 
related to environmental factors and acute changes in the vagal-sympathetic balance after training [21]. These factors may contribute to inconsistent results and discrepancies in interpretation when a single data point is used for analysis. For this reason, it is recommended to use averaged morning resting HRV data as a more consistent representation of actual changes in an athlete's autonomic balance with training compared with a single isolated value. HRV measurements (indices of vagal activity), taken in the morning hours, during some days of the week, in the decubitus position and standing, have contributed to overcome the limitations of the measurements used initially [22].

In recent years, some works showed the advantages of RMSSD, LnRMSSD and the relationship between LnRMSSD / RR intervals for training control due to typical error of measurement low [23,24] (Figure 2). The LnRMSSD may be preferred due to not significantly influenced by breathing frequency, capture levels of parasympathetic activity over a short time frame, and can be easily calculated [24]. Also, measurements of the spectral analysis of the HRV, can be used to separate patterns of "fatigue" [25].

To record the HRV, different methodologies have been used to acquire the signals, such as the electrocardiographic record at rest or in 24 hours, cell phones and smart watches connected by bluetooth to bands located in the chest that detect the $\mathrm{R}$ wave of the electrocardiogram or that can measure heart rate by photoplethysmography. Some of these devices have been validated and use specific algorithms to analyze the HRV that facilitates the biomedical training control. Also, there are software (Kubios HRV version 3.3.1) [26] that analyze in detail the RR intervals acquired by these devices (Figure 2).

\section{Conclusion}

Currently, research is advancing in the development of better HRV indicators of adaptations to training and its incorporation in smart devices in order to facilitate measurements and control of training. The implementation of the autonomic evaluation with HRV during the training process, could extend the knowledge about the cardiovascular response to the progressive increase of the physical workloads, improve the prescription of exercise and the planning of the physical stimuli, knowing of way timely adaptations, predict competitive outcome, characterize individual physiological profiles and help in the detection of early manifestations of over-training syndrome. It is recommended to record the reference HRV (one week, during a rest period) to be able to compare it with time as training loads increase. In addition, records should be made at the same time of day, ideally in the morning hours, before getting up, in decubitus and standing, and in similar conditions.

\section{References}

1. Bouchard C, An P, Rice T, Skinner JS, Wilmore JH, et al. (1999) Familial aggregation of $\mathrm{vo}(2 \mathrm{max})$ response to exercise training: Results from the heritage family study. J Appl Physiol 87: 1003-1008. Link: https://bit.ly/3eTzjbn
2. Hubal MJ, Gordish-Dressman H, Thompson PD, Price TB, Hoffman EP, et al (2005) Variability in muscle size and strength gain after unilateral resistance training. Med Sci Sports Exerc 37: 964-972. Link: https://bit.ly/3dZYE2t

3. Buford TW, Pahor M (2020) Making preventive medicine more personalized: Implications for exercise-related research. Prev Med 55: 34-36. Link: https://bit.ly/3dZni3e

4. Buford TW, Roberts MD, Church TS (2013) Toward exercise as personalized medicine. Sports Med 43: 157-165. Link: https://bit.ly/2YSRXeb

5. Meeusen R, Duclos M, Foster C, Fry A, Gleeson M, et al. (2013) Prevention, diagnosis, and treatment of the overtraining syndrome: Joint consensus statement of the european college of sport science and the american college of sports medicine. Med Sci Sports Exerc 45: 186-205. Link: https://bit.ly/2VDWOZw

6. Kiviniemi AM, Hautala AJ, Kinnunen H, Tulppo MP (2007) Endurance training guided individually by daily heart rate variability measurements. Eur J App Physiol 101: 743-751. Link: https://bit.ly/31BuboE

7. Bosquet $L$, Merkari S, Arvisais D, Aubert AE (2008) Is heart rate a convenient tool to monitor over-reaching? A systematic review of the literature. $\mathrm{Br} \mathrm{J}$ Sports Med 42: 709-714. Link: https://bit.ly/2YUPgsB

8. Botek M, McKune AJ, Krejci J, Stejskal P, Gaba A (2014) Change in performance in response to training load adjustment based on autonomic activity. Int J Sports Med 35: 482-488. Link: https://bit.ly/2D5KL65

9. Kiviniemi AM, Hautala AJ, Kinnunen H, Nissila J, Virtanen P, et al. (2010) Daily exercise prescription on the basis of hr variability among men and women. Med Sci Sports Exerc 42: 1355-1363. Link: https://bit.ly/2D2g6qa

10. Vesterinen V, Nummela A, Heikura I, Laine T, Hynynen E, et al. (2016) Individual endurance training prescription with heart rate variability. Med Sci Sports Exerc 48: 1347-1354. Link: https://bit.ly/38n6cLu

11. lellamo F, Legramante JM, Pigozzi F, Spataro A, Norbiato G, et al. (2002) Conversion from vagal to sympathetic predominance with strenuous training in high-performance world class athletes. Circulation 105: 2719-2724. Link: https://bit.ly/2Zurkv5

12. Gallo J, Álvarez D, Farbiarz J (1999) Análisis espectral de la variabilidad de la frecuencia cardíaca. latreia 12: 61. Link: https://bit.ly/2VB34G

13. Heart rate variability (1996) Standards of measurement, physiological interpretation, and clinical use. Task force of the european society of cardiology and the north american society of pacing and electrophysiology. Eur Heart J 17: 354-381. Link: https://bit.ly/2Zz2YQK

14. Gallo-Villegas A, Pérez-Idárraga A, Valencia-Gómez K, Pinzón-Castro D, Arenas-Sosa $M$, et al. (2016) Effect of dancing and nutrition education on hemodynamic and autonomic status in adults with metabolic syndrome: A randomized controlled clinical trial. Rev Colomb Cardiol 23: 467-478. Link: https://bit.ly/31CEAAD

15. Gratze G, Mayer H, Luft FC, Skrabal F (2008) Determinants of fast marathon performance: Low basal sympathetic drive, enhanced postcompetition vasodilatation and preserved cardiac performance after competition. $\mathrm{Br} \mathrm{J}$ Sports Med 42: 882-888. Link: https://bit.ly/2D2YFpr

16. Gallo J, Álvarez D, Farbiarz J (2001) Análisis en tiempo y frecuencia de la variabilidad $r-r$ en deportistas y sedentarios. Acta Med Colomb 26: 65-72. Link: https://bit.ly/2BlhNyx

17. Ospina-Uribe C, Gallo-Villegas J, Aguirre-Acevedo D, Balparda-Arias K Aristizabal-Ocampo D (2014) Diferencias en la respuesta hemodinámica y autonómica al estrés simpático entre futbolistas profesionales potentes y resistentes: Un estudio transversal. Apunts Med Esport 49: 113-122. Link: https://bit.ly/3dRSnps

18. Haskell WL, Lee IM, Pate RR, Powell KE, Blair SN, et al. (2007) Physical activity and public health: Updated recommendation for adults from the american 
college of sports medicine and the american heart association. Med Sci Sports Exerc 39: 1423-1434. Link: https://bit.ly/3eVThT1

19. Barron JL, Noakes TD, Levy W, Smith C, Millar RP (1985) Hypothalamic dysfunction in overtrained athletes. J Clin Endocrinol Metab 60: 803-806. Link: https://bit.ly/2VFsWB8

20. Uusitalo AL, Uusitalo AJ, Rusko HK (1998) Exhaustive endurance training for 6-9 weeks did not induce changes in intrinsic heart rate and cardiac autonomic modulation in female athletes. Int J Sports Med 19: 532-540. Link: https://bit.ly/38lcDyj

21. Al Haddad H, Laursen PB, Chollet D, Ahmaidi S, Buchheit M (2011) Reliability of resting and postexercise heart rate measures. Int J Sports Med 32: 598-605. Link: https://bit.ly/2YS1WQQ

22. Schmitt L, Regnard J, Millet GP (2015) Monitoring fatigue status with hrv measures in elite athletes: An avenue beyond rmssd? Front Physiol 6: 343 Link: https://bit.ly/3iqc3E4
23. Plews DJ, Laursen PB, Le Meur Y, Hausswirth C, Kilding AE, et al. (2014) Monitoring training with heart rate-variability: How much compliance is needed for valid assessment? Int J Sports Physiol Perform 9: 783-790. Link: https://bit.ly/3eVSv8z

24. Plews DJ, Laursen PB, Stanley J, Kilding AE, Buchheit M (2013) Training adaptation and heart rate variability in elite endurance athletes: Opening the door to effective monitoring. Sports Med 43: 773-781. Link: https://bit.ly/38IGBCo

25. Schmitt L, Regnard J, Parmentier AL, Mauny F, Mourot L, et al. (2015) Typology of "fatigue" by heart rate variability analysis in elite nordic-skiers. Int J Sports Med 36: 999-1007. Link: https://bit.ly/2YPRJ7x

26. Tarvainen MP, Niskanen JP, Lipponen JA, Ranta-Aho PO, Karjalainen PA (2014) Kubios hrv--heart rate variability analysis software. Comput Methods Programs Biomed 113: 210-220. Link: https://bit.ly/2BYHyEC
Discover a bigger Impact and Visibility of your article publication with Peertechz Publications

\section{Highlights}

- Signatory publisher of ORCID

* Signatory Publisher of DORA (San Francisco Declaration on Research Assessment)

* Articles archived in worlds' renowned service providers such as Portico, CNKI, AGRIS, TDNet, Base (Bielefeld University Library), CrossRef, Scilit, J-Gate etc.

* Journals indexed in ICMJE, SHERPA/ROMEO, Google Scholar etc.

* OAI-PMH (Open Archives Initiative Protocol for Metadata Harvesting)

* Dedicated Editorial Board for every journal

* Accurate and rapid peer-review process

* Increased citations of published articles through promotions

* Reduced timeline for article publication

Submit your articles and experience a new surge in publication services

(https://www.peertechz.com/submission).

Peertechz journals wishes everlasting success in your every endeavours.

Copyright: (c) 2020 Villegas JG. This is an open-access article distributed under the terms of the Creative Commons Attribution License, which permits unrestricted use, distribution, and reproduction in any medium, provided the original author and source are credited. 